\title{
Research on the Innovation Path of Business Models Based on the Market Orientation
}

\author{
Yongmei Ma $\left(D,{ }^{1}\right.$ Huafei Wei, ${ }^{2}$ Chuanshuang $\mathrm{Hu}^{3,4}$ and Chenglin Jin ${ }^{5}{ }^{5}$ \\ ${ }^{1}$ College of Mathematics and Statistics, Chaohu University, Hefei 238000, China \\ ${ }^{2}$ Business School, Anhui University, Hefei 230601, China \\ ${ }^{3}$ School of Public Affairs, University of Science and Technology of China, Hefei 230601, China \\ ${ }^{4}$ Academic Affairs Office, Chaohu University, Hefei 238000, China \\ ${ }^{5}$ School of Business, Anhui Xinhua University, Hefei 230088, China \\ Correspondence should be addressed to Chenglin Jin; 329556076@qq.com
}

Received 16 March 2021; Revised 30 March 2021; Accepted 9 April 2021; Published 6 July 2021

Academic Editor: M. Irfan Uddin

Copyright ( $) 2021$ Yongmei Ma et al. This is an open access article distributed under the Creative Commons Attribution License, which permits unrestricted use, distribution, and reproduction in any medium, provided the original work is properly cited.

\begin{abstract}
Current research considers business model innovation as a series of responses to technological change and market environment change. However, in practice, it is often business model innovation that leads to market innovation and subversion and then promotes a new round of iterative product renewal. This is because business model innovation is a value creation activity based on market demand, rather than a technology-oriented innovation behavior. Moreover, since the degree of demand manifestation varies, the degree of its influence on value creation and thus the driving mechanism for business model innovation vary significantly, and the duality of market-oriented theory is introduced to explore how firms go about achieving business model innovation based on different demand characteristics and how the results of firms' integration of market information work. Through regression analysis of 230 sample enterprises, the results show that both responsiveness and proactive market orientation have a significant positive impact on business model innovation. In contrast, market information integration has a positive regulatory effect on the two groups of relationships.
\end{abstract}

\section{Introduction}

On January 23, 2020, due to the closure of Wuhan and the nationwide foot ban caused by the spread of the New Crown Pneumonia epidemic, consumer buying behavior and patterns changed dramatically, causing all types of businesses to be severely affected and traditional business models to face a major crisis. After self-help and continuous innovation, more and more enterprises and educational institutions gradually restore their vitality by relying on network business model innovations, which brings us a problem. In the innovation of business model caused by market changes, is the predictive market change or the responsive market change easier for business model innovation? In other words, what is the difference between proactive market orientation and reactive market orientation on business model innovation, and how will market information affect the mechanism between them?
In the context of information technology-led information economy, the highly dynamic nature of the market and the rapid iteration of products force enterprises to continuously change the content of transactions, restructure transaction relationships, and disrupt transaction models through new knowledge and new technologies, so as to achieve innovation in business models and meet market demand. For example, the combination of iPhone and traditional Internet industry directly shapes the new mobile Internet industry [1]; Guazi used cars and RenRen cars across the middleman link, which greatly improves the transaction efficiency of business model and better meets the customer demand. Business model innovation is not only a core enabler of firm performance [2], but also of great strategic importance for sustained competitive advantage [3]. Business model innovation is a complex concept involving technological innovation, strategy, marketing, and 
business model science [4], and scholars of various schools have differing views on the concept, composition, and dominant logic of business models and their innovation [5-9], but none of them deny that business model innovation is a series of systematic processes of value creation activities $[10,11]$.

Business model innovation is essentially a kind of value creation activity, and it is the key to clear its value attribute driving mechanism and value occurrence mechanism. Simultaneously, the exploration of business model innovation as an outcome variable in the innovation category is beneficial to the study of its antecedents to reveal its formation mechanism. The first is the technology-driven perspective of scholars such as Zott and Amit, Yovanof and Hazapis, and Humaidan and Sabatier, who believe that technological progress and executives' attention to technology are the main driving forces of business model innovation [11-13]. Especially for information technology, disruptive technologies often bring about strategic reshaping and disruptive changes in business models [13]. However, Luo and Li [14] and Baldassarre et al. [15] believe that market orientation based on community platform and paying attention to users is the key to promote enterprise business model innovation. That is to say, the theory of technological perspective holds that business model innovation is only the need for technology commercialization, but ignores that the technology orientation of business model innovation is predicated on the market. Because market changes caused by new competitors and market rules often require firms to engage in technological learning and repeated trial-and-error by focusing on market needs to drive continuous innovation in business models [16], and the theory in the market perspective does not go further to link the essence of business model innovation to the demand characteristics of the market; the success of business model innovation is not only about focusing on customers and listening to them, but also about identifying potential customer needs, determining market preferences, discovering blue ocean of value, and achieving effective market orientation and active response.

Business model innovation is a process of creating value, transmitting and obtaining value. In contrast, a company's marketing activities are a series of actions to identify, understand, and satisfy customer needs [17]. By digging deeper into the existing needs of customers and effectively guiding future needs, enterprises can redefine the value proposition of customers and make products bring higher value to consumers by providing better consumer experience in the interaction with end-users, and then achieve systematic innovation of business model components such as customer relationship, partner network, cost structure, and profit model. End-users are the power source of business model innovation. The focus on end-user needs determining the availability of the resources needed for business model innovations. Zott and Amit argue that the core logic of value creation lies in defining core customers rather than $\mathrm{R} \& \mathrm{D}$ investments [11]. Scholars like Gadrey state that it is the market orientation of different innovation models that is the antecedent characteristic of service model innovation [18]. Therefore, the various focus on demand determines the difference of enterprises' insight into the future market, and there are also differences in the degree and form of value created by their market activities. The integration of the corresponding market demand information will even affect the rate and effect of the transaction content, transaction relationship, and transaction model innovation of the enterprise business model.

Therefore, combined with the market-oriented theory, this study explores the power source of business model innovation further from the perspective of customer demand, in order to study the mechanism of proactive market orientation and reactive market orientation on business model innovation deeply. And the regulatory effect of market information integration. Thus, it will help enterprises to clarify the dynamic mechanism of business model innovation, have a targeted insight into the market, integrate market information fully and reasonably, make better use of user resources, accelerate and enhance business model innovation, and meet market demand, enhancing competitive advantage, sustained and healthy development.

\section{Materials and Methods}

\subsection{Theoretical Basis and Research Hypothesis}

2.1.1. The Business Model Innovation's Influence of Market Orientation. Business model innovation is a process in which an enterprise establishes a whole system centered on value creation $[4,6-8,10,11]$. Its value creation is reflected in two aspects: first, for transaction cost economics, enterprises improve transaction efficiency by reducing transaction costs, thus upgrading the value of existing resources [7]. They reduce complexity, uncertainty, information asymmetry, and transaction risk by aggregating demand and speeding up transactions to find value realization points for the firm itself and its partners. The second is to obtain new information, use new technologies, and develop new product markets to create new value. Such novel business models often require connecting new players, changing the way resources are allocated within the enterprise, revolutionizing transaction structures, providing new transaction content, and designing new transaction governance models. Cost-driven value creation that pays attention to efficiency and new value discovery caused by exploring market opportunities are two basic ideas for enterprises to innovate business models based on the market. The value network theory also shows that only when enterprises continue to create and enhance customer value can they win the competition $[19,20]$. When aiming at and expanding into emerging markets, companies must understand the adaptability of the value delivery path of the original business model and the multilevel nature of customer needs [21] to better create and explore customer value and then construct value networks to innovate business models. Moreover, when companies design their business models, they can only achieve the strategic value objectives of the organization based on consumer preferences and customer needs. Therefore, business model innovation should not only pay attention to the demand-driven role but also consider the 
differentiated impact of different characteristics of customer demand.

According to transaction cost economics, there is a cost in the transaction [22]. The circulation of products will lead to the increase of transaction costs, and this kind of transaction cost is positively related to the degree of refinement of the division of labor in the value chain, so in order to ensure professionalism and reduce the agency cost between enterprises and consumers, enterprises need to incorporate end-users into their own design and development links to form a business model of close cooperation between enterprises and users. It enables both parties to share the value benefits of reducing transaction costs [23]. Therefore, insight into customer needs is the key. An enterprise should have a reactive market-oriented concept to discover, understand, and meet the actual needs of customers [17], so as to reflect customer problems in the production process and value chain of the enterprise. These business model components, such as the company's target customers, value proposition, channel access, customer relationships, core competencies, key businesses, cost structure, partner network, and revenue model, are then adjusted to achieve innovation in the existing model. Bohnsack et al. study of business models in the electric vehicle market noted that adjustments in business model components such as value-added service offerings, battery exchange services, and extended warranties can quickly open the electric vehicle market. Thus, the evolution and innovation of business models can also be facilitated by the alignment of cost models, partners, and value networks rather than significant adjustments in the value proposition [24]. Anchoring a successful business model is often extremely difficult, but it is easier to achieve progressive innovation by constantly selecting, adjusting, and upgrading existing business models [10].

Focusing on efficiency as the main source of value creation, companies can achieve efficiency maximization and demand satisfaction through reactive market orientation, which leads to business model innovation. First, deeper exploration of existing needs can improve product performance and promote the diversity of products in the current market, thus enriching transactions and reducing user search costs. Secondly, from the perspective of the transaction structure of the business model, the effective solution of customer problems can win loyal customers for the enterprise, thus strengthening the connection between the enterprise and the user, and making it easier for the enterprise to gain the understanding and support of the user by changing the transaction mode. It also reduces the conversion cost of changing the status of the existing value chain. Finally, from the perspective of transaction governance of business models, familiarity with existing markets helps companies overcome the "when, where, and who to solve" problem. Mastery of market intelligence can promote enterprises to implement differentiated strategies for different market segments and how to provide products. In a word, the enterprise executive reactive market orientation can make appropriate changes and adjustments to the trade content, trade structure, and transaction governance of the business model according to the effective market feedback, so as to realize the innovation of the business model. Therefore, the following assumption is proposed:

H1 Reactive market orientation affects business model innovation positively.

Redesigning the business model is a radical business model innovation. By redefining the value proposition, constructing a new value system and designing a new transaction mechanism through the identification of potential customer demand and anticipation of future needs, we can be more proactive in changing transaction content, transaction structure, and transaction governance. This deeper innovation can no longer be achieved by market feedback and meeting customer needs, but must rely on more forward-looking market orientation. This forward-looking market orientation aims to identify, understand, and meet the potential and future needs of customers. With the help of cooperation with leading customers and long-term observation of the market, enterprises can predictably cultivate market demand [25]. For example, Cargo Lala uses the Internet platform to collect idle vehicles to solve the problem of "difficulty in hauling goods" for users, reduces the information asymmetry of ordinary users, absorbs part-time owners into the value creation process, and changes the role of full-time drivers in the value network. Customer participation and cooperation is not only to guide the demand, but also to create value together. The essence of business model innovation lies in value creation, and value lies in customer perception [14]. Hence interaction with customers is a prerequisite to identify, understand, and meet their potential need. Secondly, when pioneering marketoriented enterprises explore and tap a hidden need, they often need to cross corporate boundaries and cooperate more widely to obtain external ideas and knowledge [11]. Enterprises not only need to pay attention to customers and competitors, but also need to improve their ability to explore and develop new knowledge and technology with the help of other market participants such as cooperative enterprises, research institutions, and consulting organizations [26], to better and more efficiently identify and meet customers' potential needs, and to realize the refinement of product concepts, the creation of customer value, and the design and planning of business models, so as to absorb more stakeholders. It is more conducive for enterprises to achieve innovation in business model transaction structure and transaction governance by entering the enterprise value ecosystem and uniting market participants to build a new value network. Therefore, the following hypothesis is proposed:

$\mathrm{H} 2$ First-mover market orientation is conducive to promote business model innovation. 
2.1.2. The Regulatory Role of Market Information Integration. Value network theory suggests that value creation and delivery requires continuous improvement of input conversion efficiency to achieve integration of customer value and firm value $[19,20]$. How to effectively transform customer resources into the source of enterprise value creation is often the key to business model innovation [6] because customers often need not specific products, but a series of problem solutions to meet their needs [10]. As market dynamics and high uncertainty intensify, the information and knowledge required by companies seeking product solutions must also be more extensive and in-depth, as also identified by Denicolai et al. [27] study who suggested that business model innovation needs to match the external and internal knowledge of the company; therefore, the integration of market information of the company is crucial. Under the higher integration of market information, market-oriented enterprises can meet the market demand more effectively and accelerate the innovations of the business model; in contrast the poor integration of market information leads to the reduction of the ability and effect of customer value transmission because of insufficient or mismatched information, thus weakening the effects of enterprise innovation. Therefore, enterprises must improve the efficiency and level of resource allocation between different internal functional departments, while improving the efficiency of communication and coordination with external partners, to improve transaction efficiency in the value chain. Reduce transaction costs caused by difficulties in coordination and inefficient allocation of resources between enterprises and partners. Due to the dispersion and complexity of customer demand information, how to extract the most effective and suitable product solution from the numerous demand characteristics requires enterprises to continuously integrate and match their own knowledge with market knowledge and continuously adjust the transaction configuration and resource combination with different business partners to ensure the success of business model innovation. In the condition of high market information integration ability, there is no doubt that enterprises can better merge, sort out, and refine the existing market information, so as to develop mature products that maximize meeting the needs of the current market and accelerate the reengineering and upgrading of business value.

On the other hand, through the effective integration of all kinds of market information, reactive market-oriented enterprises can better discover and open up new market opportunities, so as to drive market development to improve their ability to develop the market and then accelerate business model innovation [28]. The business model innovation's essence is to create more business value for enterprises and the generation and transmission of value are reflected in the value chain of enterprises. Therefore, effective market information integration can strengthen the linkage and dispatches of heterogeneous resources owned by participating enterprises in the value chain and thus build a tight value network to promote the creation, transmission, and acquisition of value. When enterprises discover potential demand dividends, the more rapid and effective integration of relevant knowledge often means a great improvement in the efficiency and effectiveness of value development [14], and Market-oriented enterprises will actively extend and across their boundaries. The continuous absorption and use of external knowledge can enhance the enterprise's identification and understanding of the potential market demand. And then accelerate the innovations and even reconstruction of the enterprise's operation system and value model [4]. Based on this, the following hypothesis is proposed:

H3a Market information integration can strengthen the positive impact of reactive market orientation on business model innovation.

$\mathrm{H} 3 \mathrm{~b}$ Market information integration can strengthen the positive impact of proactive market orientation on business model innovation.

To sum up, the framework model diagram of this paper is shown in Figure 1.

\subsection{Research Design}

2.2.1. Research Sample. In this study, questionnaire survey method was used and high-tech enterprises were selected as the respondents because high-tech enterprises need not only technological innovation but also defining market demand to capture users. The empirical study by Wang et al. which used oil companies as the research target also showed that it is also of great theoretical and practical value to study business model innovation in traditional technology manufacturing industries [29]. According to the principle of snowball sampling, the questionnaire will be put in three following forms: first, select senior executives of high-tech enterprises who meet the requirements in the social network of the research team and ask them to answer them according to the requirements; second, they are selectively distributed among the MBA students of our school; invite them to promote the research by forwarding it to social circles on their behalf upon request. Third, relying on the project support of the project team of "Yangtze River Delta Region Port Logistics Linkage Development Research," questionnaires were distributed among the researched enterprises. A total of 300 middle and senior managers from 300 enterprises participated in the questionnaire survey. After removing the invalid data, 230 valid sample data were obtained. The basic information of the sample is as follows: $36.52 \%$ for large enterprises, $28.26 \%$ for medium-sized enterprises, $35.22 \%$ for small enterprises, $45.22 \%$ for Chinese enterprises, and $54.78 \%$ for private enterprises; the age of enterprises is between 3 and 80 years old, and the average age of enterprises is 16.49 years. The industry selects high-tech manufacturing, of which information technology accounts for $10.43 \%$, advanced manufacturing accounts for $20 \%$, biomedicine accounts for $15.65 \%$, semiconductor industry accounts for $16.96 \%$, new materials account for $8.69 \%$, electronic communications account for $15.22 \%$, and others account for $13.04 \%$. 


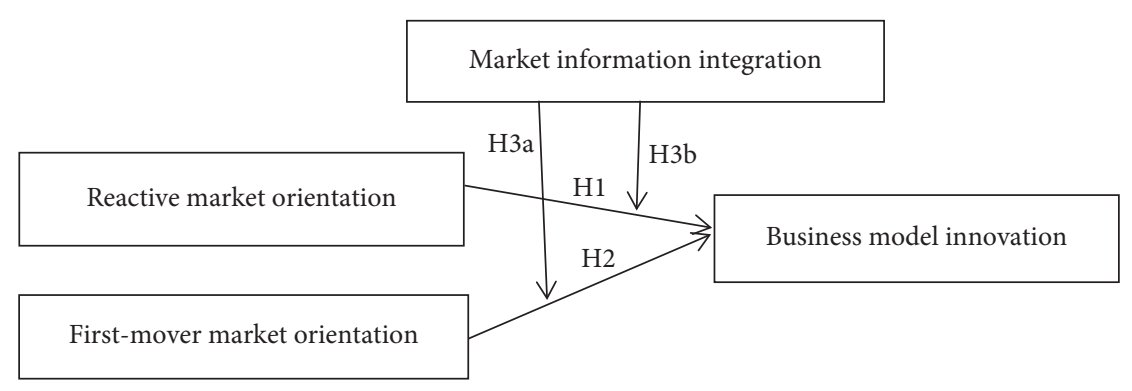

FIGURE 1: Research framework model diagram.

2.2.2. Variable Measurements. This study involves four variables: reactive market orientation, proactive market orientation, market information integration, and business model innovation. To ensure the validity and reliability of the measuring instrument, the formation of the initial questionnaire followed the authoritative maturity scale in the existing literature at home and abroad, using the Likert 5 scale, and the interviewees were asked to evaluate the description sentences of the scale according to the actual situation. The answers range from 1 "very disagree" to 5 "very much agrees." After the initial scale was determined, we conducted in-depth interviews with more than a dozen people, including executives, professionals, and related scholars and repeatedly revised the items in the questionnaire. Then, according to the feedback of the interviewees in the presurvey, the final questionnaire was formed after readjustment.

The measurement of market orientation is based on the scale developed by Wang et al. [29], Zhang and Duan [30], and other researchers, which is mainly measured by two dimensions: proactive market orientation and reactive market orientation. Reactive market orientation includes "Improving customer satisfaction is our main business goal," "Our company continuously monitors and satisfies customer needs," "We regularly and systematically evaluate the level of customer satisfaction," and "We frequently communicate with customers about our good or bad strategies in the market." Proactive market orientation includes "We anticipate market trends," "We constantly try to identify additional needs that our customers are not yet aware of," "We incorporate the needs that our customers cannot yet articulate into our new products and services," and "We look for new opportunities in areas where customers have difficulty describe their needs accurately."

Market information integration draws on Dong Zhenlin's research on market knowledge integration, including "routine and regular formal reports and records to conduct learning activities," "regular meetings to facilitate information sharing among corporate members," "face-toface discussions by forming teams that include different department and individuals, such as marketing, R\&D, and production," "formal analysis of failed new product development projects," "formal analysis of successful new product development projects," and "use of experts and consultants to coordinate and integrate knowledge and information between different departments and individuals" [31].

According to the research of Pang and Yuan [32], the business model innovation scale includes five items: "our business model adopts innovative trading methods," "our business model can provide value-added products or services," "our business model creates new profit ways," "our business model creates new profit points," and "our business model is novel."

\subsection{Statistical Analysis}

2.3.1. Reliability and Validity Analysis. To verify the validity of the questionnaire, this paper mainly uses two kinds of software: SPSS21.0 and AMOS21.0. In this paper, Cronbach $\alpha$ coefficient was selected as the test index of the reliability of the scale. At the same time, confirmatory factor analysis method was used to test the construct validity of the four subscales. Cronbach $\alpha$ value of reactive market orientation, proactive market orientation, market information integration and business model innovation are shown in Table 1. The smallest coefficient is 0.861 , which is greater than the reference value 0.7 , which meets the Standard. The meanvariance extracted values (AVE) for each variable were also calculated and listed on the diagonal of Table 1, with a minimum value of 0.806 , which is greater than the reference standard of 0.50 . All AVE values were greater than the correlation coefficient, indicating good convergent validity for the four measurement scales involved in this study.

The average value, standard deviation, and Pearson correlation coefficient matrix of the four variables in this study is shown in Table 1. From Table 1, we can see that there is a significant positive correlation between business model innovation and reactive market orientation $(\beta=0.580, p<0.01)$ and between business model innovation and proactive market orientation $(\beta=0.292, p<0.01)$. It is beneficial to further regression analysis. At the same time, there is a significant correlation between business model innovation and market information integration, indicating the rationality of selecting regulatory variables in this study. The maximum correlation coefficient between the four variables is 0.580 , which does not have a high correlation, which avoids the autocorrelation of further regression and meets the requirements of variable differences. 
TABLE 1: Correlation table.

\begin{tabular}{|c|c|c|c|c|c|c|c|c|c|}
\hline & 1 & 2 & 3 & 4 & 5 & 6 & 7 & 8 & Cronbach's $\alpha$ \\
\hline Reactive market orientation & $(0.898)$ & & & & & & & & 0.872 \\
\hline Proactive market orientation & $0.257^{* *}$ & $(0.908)$ & & & & & & & 0.875 \\
\hline Market information integration & $0.250^{* *}$ & $0.238^{* *}$ & $(0.832)$ & & & & & & 0.883 \\
\hline Business model innovation & $0.580^{* *}$ & $0.292^{* *}$ & $0.527^{* *}$ & $(0.806)$ & & & & & 0.861 \\
\hline Enterprise age & -0.022 & 0.064 & 0.076 & 0.006 & - & & & & - \\
\hline Enterprise size & -0.037 & 0.113 & 0.057 & 0.040 & -0.021 & - & & & - \\
\hline Industry category & -0.037 & $0.139^{*}$ & 0.09 & 0.058 & -0.023 & $0.536^{* *}$ & - & & - \\
\hline Enterprise nature & 0.070 & -0.125 & -0.077 & -0.044 & -0.019 & $-0.551^{* *}$ & $-0.551^{* *}$ & - & - \\
\hline Mean value & 4.073 & 2.881 & 4.232 & 3.976 & 16.51 & 1.991 & 3.909 & 0.452 & - \\
\hline Standard deviation & 0.715 & 1.027 & 0.798 & 0.654 & 14.57 & 0.848 & 1.941 & 0.497 & - \\
\hline
\end{tabular}

Note. The bold part of the diagonal line in the brackets is the square root value of AVE; the symbol * represents the significance level of $p<0.05$; the symbol ** represents the significance level of $p<0.01$.

2.3.2. Regression Analyses. According to the above hypothesis, this study uses the linear regression method to test the hypothesis through SPSS21.0 software. The hypothesis test results are shown in Table 2. The running results show that all the regression models have passed the $F$ test, and the overall significance of the model is good.

(1) Model2 adds the independent variable of reactive market orientation on the basis of Model1 in Table 2. The results show that reactive market orientation positively affects business model innovation results significantly $(\beta=0.522, p<0.001)$. The results of model 3 show that proactive market orientation has a significant positive impact on business model innovation $(\beta=0.178, p<0.001)$, so $\mathrm{H} 1$ and $\mathrm{H} 2$ are verified.

(2) In order to verify the regulatory effect, we first calculate the interactive terms between reactive market orientation and market information integration and then calculate the interactive items between proactive market orientation and market information integration, which are put into Model5 and Model6, respectively. As shown in Table 2, the market information integration coefficient of reactive market orientation $*$ in Model5 is positive and significant $(\beta=0.124, p<0.01)$, and the market information integration coefficient of proactive market orientation $*$ in Model6 is positive and significant $(\beta=0.107, p<0.01)$, so $\mathrm{H} 3 \mathrm{a}$ and $\mathrm{H} 3 \mathrm{~b}$ are verified.

\section{Research Conclusion}

This paper studies the dynamic mechanism of business model innovation from the essence of business model, combined with market-oriented theory. It divides demand characteristics into reactivity and preactivity, thus studying two different ideas and paths of business model innovation: first, through in-depth excavation of existing demand to promote efficiency and value upgrading, so as to achieve business model innovation. The second is to realize new value creation by developing potential demand to launch new products and services and to develop new markets. Moreover, this study argues that the complexity of market demand itself is regulated by the ability of enterprises to integrate market information, and that only when demand characteristics are transformed into value characteristics can enterprises create value and eventually achieve business model innovation. The empirical findings of this paper are also helpful to better cognize business model innovation from the perspective of marketing and expand the related research in the field of market and business model.

The theoretical contributions are as follows: first of all, most of the existing studies believe that business model innovation is inseparable from the influence of market factors, but do not specifically study the mechanism of business model innovation from the perspective of market orientation. Starting from the characteristics of demand and according to the reality and potential of market demand, this study divides market orientation into proactive market orientation and reactive market orientation. It discusses the valuable sources of business model innovation based on value creation, which enriches and demonstrates the research of Zott, Luo Min, and Li Liangyu. It also supports the research conclusion that Luo Min and Li Liangyu believe that the key to business model innovation in the network era is to connect dividends and customer needs. Therefore, this study promotes the integrated development of marketoriented theory and business model theory.

Second, the positive effect of two aspects of market orientation promotes the study of the category of business model innovation sources and further expands and deepens the study of the role mechanism of market orientation in influencing business model innovation. Aspara et al. [33] in their study pointed out based on theoretical analysis that preemptive market orientation can promote business model innovation, but argued that reactive market orientation has no significant effect, and no further empirical studies and indepth analysis were conducted. Based on the value theory, this study puts forward two different market-oriented paths of business model innovation, which enriches the research on the dynamic mechanism of business model innovation and broadens the research field of business model innovation.

Finally, the moderating effect of market information integration not only refines the influence mechanism of market orientation on business model innovation, but also 
TABle 2: Regression coefficient table.

\begin{tabular}{|c|c|c|c|c|c|c|}
\hline & Model 1 & Model 2 & Model 3 & Model 4 & Model 5 & Model 6 \\
\hline Enterprise age & 0.001 & 0.001 & 0.001 & -0.002 & -0.001 & -0.002 \\
\hline Enterprise nature & $-0.720^{*}$ & $-0.793^{*}$ & $-0.678^{*}$ & -0.088 & -0.246 & -0.110 \\
\hline Medium-sized enterprise & -0.306 & -0.210 & -0.228 & -0.180 & -0.115 & -0.171 \\
\hline Small business & -0.750 & -0.558 & -0.466 & -0.319 & -0.189 & -0.205 \\
\hline Information technology industry & 0.039 & 0.045 & 0.026 & -0.035 & -0.024 & -0.018 \\
\hline Machinery manufacturing industry & 0.013 & -0.010 & -0.105 & 0.123 & 0.084 & 0.082 \\
\hline Biomedical industry & -0.610 & -0.627 & -0.698 & -0.004 & -0.141 & -0.078 \\
\hline Energy industry & 0.061 & -0.224 & -0.235 & 0.298 & 0.014 & 0.167 \\
\hline Electronic communication industry & 0.214 & -0.038 & -0.131 & 0.312 & 0.043 & 0.159 \\
\hline Other industries & 0.034 & -0.152 & -0.265 & 0.088 & -0.126 & -0.047 \\
\hline Reactive market orientation & & $0.522^{* * *}$ & & & -0.120 & \\
\hline Proactive market orientation & & & $0.178^{* * *}$ & & & $-0.388^{*}$ \\
\hline Market information integration & & & & $0.597^{* * *}$ & 0.028 & $0.323^{* *}$ \\
\hline Reactivity $*$ information integration & & & & & $0.124^{* *}$ & \\
\hline Proactive $*$ information integration & & & & & & $0.107^{* *}$ \\
\hline$R$-square & 0.059 & 0.378 & 0.235 & 0.547 & 0.717 & 0.579 \\
\hline Adjusted $R$-square & 0.017 & 0.343 & 0.189 & 0.528 & 0.703 & 0.555 \\
\hline$F$ value & 1.357 & $11.79^{* * *}$ & $3.08^{* * *}$ & $24.19^{* * *}$ & $42.27^{* * *}$ & $22.75^{* * *}$ \\
\hline
\end{tabular}

Note. Dummy variable processing: large-scale enterprises are the benchmark for enterprise types; semiconductors are the benchmark for industry categories. The symbol * represents the significance level of $p<0.05$; the symbol ${ }^{* *}$ represents the significance level of $p<0.01$; and the symbol ${ }^{* * *}$ represents the significance level of $p<0.001$.

advances the contextual study of business model innovation. However, in the existing research on the dynamic mechanism and path of business model innovation, we often focus on its antecedents and intermediary variables and pay relatively little attention to the regulatory variables and boundary conditions of enterprise business model innovation. It is not clear under which conditions the impact of market orientation on this kind of business model innovation is stronger or weaker. Market information integration is not only a further explanation of the demand attribute of market orientation, but also a complete model framework of market orientation on business model innovation.

The practical contribution of this paper is in the following two aspects: on the one hand, due to the different effects of the manifestation and potential of demand on business model innovation, therefore, the business model innovation of enterprises can consider the two market-oriented strategies of responsiveness and initiative based on their own business reality and market situation; that is, enterprises can choose to gradually adjust the transaction relationship and transaction content through gradual business change to realize business model innovation. Or, enterprises can develop new markets and design new business models by creating demand and surpassing existing market mental models, so as to achieve business model innovation.

On the other hand, when an enterprise implements business model innovation, in addition to considering two different ideas of demand guidance, it should consider how to choose cooperation with supply chain node enterprises and neighboring enterprises and how to coordinate the resources of different departments to promote a better grasp of market opportunities and then accelerate the identification, acquisition, absorption, and innovation of market knowledge and information through the integration of market intelligence and information. Through the integration of market intelligence and information, we accelerate the process of identifying, acquiring, absorbing, and innovating market knowledge and information, enhance the ability of realizing the value of real market demand and potential demand, increase the possibility of turning demand into profit, and promote the real realization of business model innovation.

This paper also has the following shortcomings: first of all, the snowball sampling method is adopted in this paper, which solves the problem that the executive questionnaire is difficult to collect to some extent, but it is also affected by the research team's own social network and sample resources. In the follow-up study, the scope of the survey can be extended to more random and extensive sample enterprises. Second, the issue of bargaining power of partner firms and their role in the process of market demand value transformation has a direct impact on the dynamic mechanism of business model innovation and deserves further study. In addition, this paper is based on a high-tech industry context, but there is still a large heterogeneity within the industry, and thus subindustry studies can be conducted in future research.

\section{Data Availability}

The data used to support the findings of this study are available from the corresponding author upon request.

\section{Conflicts of Interest}

The authors declare that they have no conflicts of interest.

\section{Authors' Contributions}

Conceptualization was done by Y.M., C.S., and C.L.; methodology was carried out by Y.M.; data curation was performed by Y.M.; original draft was prepared by Y.M., C.S., and C.L.; reviewing and editing were carried out by 
Y.M.; visualization was performed by Y.M., C.S., and C.L.; supervision was done by C.S.

\section{Acknowledgments}

The project was supported by the key projects of Anhui Provincial Natural Science Foundation (KJ2016A505), Anhui University Humanities and Social Sciences Research Project (SK2019A0545), Anhui Online Major Teaching Reform Project (2020zdxsjg234), Domestic Visiting Training Project for Outstanding Young Backbone Talents in Colleges and Universities (gxgnfx2018034), Anhui Quality Engineering Project (2018mooc508 and 2019mooc273), and Teaching Team Project of Chaohu University (ch20jxtd02).

\section{References}

[1] H. Xiong, G. Wu, and Y. Wang, "The study of innovation pathways based on market trajectory: evidence from apple's case," International Journal of Science, Technology and Management, vol. 47, no. 7, pp. 124-132, 2013.

[2] Y. Taran, H. Boer, and P. Lindgren, "A business model innovation typology," Decision Sciences, vol. 46, no. 2, pp. 301-331, 2015.

[3] Q. Xia and H. Lou, "Business model rigidity: structural composition and evolutionary mechanism," China Industrial Economics, vol. 8, pp. 148-160, 2014.

[4] X. Wang and D. Dong, "Review and Prospect of the concept of business model innovation," Foreign Economics \& Management, vol. 35, no. 11, pp. 29-36, 2013.

[5] R. Amit and C. Zott, "Crafting business architecture: the antecedents of business model design," Strategic Entrepreneurship Journal, vol. 9, no. 4, pp. 331-350, 2015.

[6] R. Amit and C. Zott, "Value creation in E-business," Strategic Management Journal, vol. 22, no. 6-7, pp. 493-520, 2001.

[7] C. Zott and R. Amit, "Business model design and the performance of entrepreneurial firms," Organization Science, vol. 18, no. 2, pp. 181-199, 2007.

[8] A. Osterwalder, The Business Model Ontology-A Proposition in a Design Science Approach, Universitéde Lausanne, Lausanne, Switzerland, 2004.

[9] A. Osterwalder and Y. Pigneur, Business Models Are New, China Machine Press, Beijing, China, 2011.

[10] D. J. Teece, "Business models, business strategy and innovation," Long Range Planning, vol. 43, no. 2-3, pp. 172-194, 2010.

[11] C. Zott and R. Amit, "Business model design: an activity system perspective," Long Range Planning, vol. 43, no. 2-3, pp. 216-226, 2010.

[12] S. A. Humaidan and V. Sabatier, "Strategic renewal in times of environmental scarcity: the mediating role of technology in business model evolution," Journal of Organizational Change Management, vol. 30, no. 1, pp. 106-120, 2017.

[13] G. S. Yovanof and G. N. Hazapis, "Disruptive technologies, services, or business models?" Wireless Personal Communications, vol. 45, no. 4, pp. 569-583, 2008.

[14] M. Luo and L. Li, "The innovation model of business in Internet era: from value creation perspective," China Industrial Economics, vol. 57, no. 1, pp. 95-107, 2015.

[15] B. Baldassarre, G. Calabretta, N. M. P. Bocken, and T. Jaskiewicz, "Bridging sustainable business model innovation and user-driven innovation: a process for sustainable value proposition design," Journal of Cleaner Production, vol. 147, no. 3, pp. 175-186, 2017.

[16] M. Sosna, R. N. Trevinyo-Rodríguez, and S. R. Velamuri, "Business model innovation through trial-and-error learning," Long Range Planning, vol. 43, no. 2-3, pp. 383-407, 2010.

[17] J. C. Narver, S. F. Slater, and D. L. Maclachlan, "Responsive and proactive market orientation and new-product success $*$," Journal of Product Innovation Management, vol. 21, no. 5, pp. 334-347, 2004.

[18] J. Gadrey, F. Gallouj, and O. Weinstein, "New modes of innovation," International Journal of Service Industry Management, vol. 6, no. 3, pp. 4-16, 1995.

[19] P. Kothandaraman and D. T. Wilson, "The future of competition," Industrial Marketing Management, vol. 30, no. 4, pp. 379-389, 2001.

[20] D. Bovet, J. Martha, and M. Consulting, Value Nets: Breaking the Supply Chain to Unlock Hidden Profits, John Wiley \& Sons, New York, NY, USA, 2000.

[21] N. Sinkovics, R. R. Sinkovics, and M. Yamin, "The role of social value creation in business model formulation at the bottom of the pyramid - implications for MNEs?" International Business Review, vol. 23, no. 4, pp. 692-707, 2014.

[22] O. E. Williamson, "The economics of organization: the transaction cost approach," American Journal of Sociology, vol. 87, no. 3, pp. 548-577, 1981.

[23] Y. Liu and J. Xie, "Business model innovation of manufacturing enterprises under the strategy of sustainable development," International Journal of Science Technology \& Management, vol. 1, pp. 53-62, 2015.

[24] R. Bohnsack, J. Pinkse, and A. Kolk, "Business models for sustainable technologies: exploring business model evolution in the case of electric vehicles," Research Policy, vol. 43, no. 2, pp. 284-300, 2014.

[25] S. Ozdemir, D. Kandemir, and T.-Y. Eng, "The role of horizontal and vertical new product alliances in responsive and proactive market orientations and performance of industrial manufacturing firms," Industrial Marketing Management, vol. 64, no. 7, pp. 25-35, 2017.

[26] K. Grigoriou and F. T. Rothaermel, "Organizing for knowledge generation: internal knowledge networks and the contingent effect of external knowledge sourcing," Strategic Management Journal, vol. 38, no. 2, pp. 395-414, 2017.

[27] S. Denicolai, M. Ramirez, and J. Tidd, "Creating and capturing value from external knowledge: the moderating role of knowledge intensity," R\&D Management, vol. 44, no. 3, pp. 248-264, 2014.

[28] T. Saebi, L. Lien, and N. J. Foss, "What drives business model adaptation? The impact of opportunities, threats and strategic orientation," Long Range Planning, vol. 50, no. 5, pp. 567-581, 2017.

[29] B. Wang, S. Zhang, and L. Wang, "A cross-level study on business mode innovation," Employee Entrepreneurship and Corporate Culture, vol. 28, no. 4, pp. 39-51, 2016.

[30] J. Zhang and Y. Duan, "An empirical study on the impact of market oriented equilibrium on product innovation performance of manufacturing enterprises," Management World, vol. 12, pp. 119-130, 2010.

[31] Z. Dong, External Knowledge Search, Knowledge Integration Mechanism and Firm Innovation Performance: The Moderating Effect of External Environment Characteristics, Jilin University, Changchun, China, 2017.

[32] C. Pang, L. Yuan, and G. Duan, "Integrative capability and firm performance: the mediating effect of business model 
innovation," Journal of Management Science, vol. 28, no. 5, pp. 31-41, 2015.

[33] J. Aspara, J. Hietanen, and H. Tikkanen, "Business model innovation vs replication: financial performance implications of strategic emphases," Journal of Strategic Marketing, vol. 18, no. 1, pp. 39-56, 2010. 